Discussion Paper No. 03-12

\title{
The Decision of Venture Capitalists on Timing and Extent of IPOs
}

Tereza Tykvová

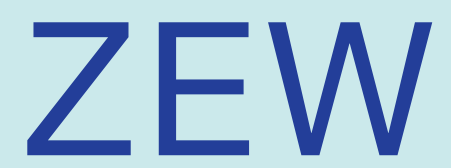

Zentrum für Europäische Wirtschaftsforschung GmbH

Centre for European

Economic Research 
Discussion Paper No. 03-12

\title{
The Decision of Venture Capitalists on Timing and Extent of IPOs
}

\author{
Tereza Tykvová
}

Download this ZEW Discussion Paper from our ftp server:

ftp://ftp.zew.de/pub/zew-docs/dp/dp0312.pdf

Die Discussion Papers dienen einer möglichst schnellen Verbreitung von neueren Forschungsarbeiten des ZEW. Die Beiträge liegen in alleiniger Verantwortung der Autoren und stellen nicht notwendigerweise die Meinung des ZEW dar.

Discussion Papers are intended to make results of ZEW research promptly available to other economists in order to encourage discussion and suggestions for revisions. The authors are solely responsible for the contents which do not necessarily represent the opinion of the ZEW. 


\section{Non-technical Summary}

Venture capitalists have to exit their investment after a certain period of time. This paper analyzes the exit channel initial public offering (IPO). Hereby, it concentrates on the explanation of the timing of the IPO, the offer price and the fraction of shares the venture capitalist sells at the IPO (extent of the IPO). The theoretical model has two periods and distinguishes between two firm types and different project kinds. As an active investor, the venture capitalist knows the firm better than the potential new investors who buy shares at the IPO. Another difference between the venture capitalist and the new investors is that the former offers not only money but also managerial support that may enhance the value of the firm. This non-monetary contribution is lost after the IPO. The model considers five possible exit channels: (1) a complete IPO after the first period ( = the venture capitalist sells all his shares), (2) an IPO after the first period with a lock-up ( $=$ the venture capitalist commits himself to retain some of his shares until the end of the second period), (3) a complete IPO after the second period, (4) a liquidation after the first period and (5) a liquidation after the second period. The venture capitalist maximizes his profit which equals the revenues from selling the shares minus the cost. Under certain conditions, the following (separating) equilibrium emerges: High-quality firms with less consulting intensive projects go public after the first period and the venture capitalist uses a lock-up. High-quality firms with more consulting intensive projects go public after the second period without a lock-up. Low-quality firms are liquidated after the first period. The model provides a number of empirically testable implications. 


\title{
The Decision of Venture Capitalists on Timing and Extent of IPOs
}

\author{
Tereza Tykvová ${ }^{1}$ \\ Centre for European Economic Research (ZEW) \\ March 2003
}

\begin{abstract}
We analyze the venture capitalist's decision on the timing of the IPO, the offer price and the fraction of shares he sells in the course of the IPO. A venture capitalist may decide to take a company public or to liquidate it after one or two financing periods. A longer venture capitalist's participation in a firm (later IPO) may increase its value while also increasing costs for the venture capitalist. Due to his active involvement, the venture capitalist knows the type of firm and the kind of project he finances before potential new investors do. This information asymmetry is resolved at the end of the second period. Under certain assumptions about the parameters and the structure of the model, we obtain a single equilibrium in which high-quality firms separate from low-quality firms. The latter are liquidated after the first period, while the former go public either after having been financed by the venture capitalist for two periods or after one financing period using a lock-up. Whether a strategy of one or two financing periods is chosen depends on the consulting intensity of the project. In the separating equilibrium, the offer price corresponds to the true value of the firm.
\end{abstract}

JEL Codes: D80, G24, G32

Keywords: Venture Capital, IPO, Lock-up, Timing

\footnotetext{
${ }^{1}$ I am grateful for helpful comments from Uwe Walz, Katrin Ullrich, participants of the FMA European Meeting in Copenhagen and the 9th Symposium on Finance, Banking, and Insurance in Karlsruhe. Further, I want to thank to Alice Lookofsky for the proof reading. Financial support by the German Research Foundation (DFG) is gratefully acknowledged. Contact: tykvova@zew.de
} 


\section{Introduction}

The life of a venture capital fund is limited: in the US it is usually set at a maximum of ten years (see Sahlman, 1990). After this period, the capital providers (typically large institutional investors) want to harvest the revenues from their investments in venture capital funds and evaluate the venture capitalists. Therefore, the investment period of venture capitalists in young firms is short, usually 3 to 7 years (see Barry, 1994). The returns from their investment are the capital gains raised after a successful build-up of the business rather than regular dividend returns (see OECD, 2002). Hence, the development of a viable venture capital market essentially depends on the existence of suitable exit routes, which provide opportunities for high returns.

Initial public offerings (IPOs) are generally considered to be the most profitable exit route (see Bygrave and Timmons, 1992). Second-tier or parallel markets are the place where most of the venture backed firms that go public are initially listed. The existence of such markets for young dynamic firms is considered to be essential for the venture capital industry (see e.g. Black and Gilson, 1998). Several empirical papers confirm the positive role of a viable IPO market on venture capital activity: Jeng and Wells (2000) found out that IPOs were the most powerful driver of venture capital investing. Gompers (1998) saw a surging market for venture-backed IPOs as one of the main reasons for the dramatic increase in venture capital commitments in the US. In our paper, we concentrate on this exit channel.

In practice, we observe that (1) venture-backed firms go public at different times in the firms life and after being financed by venture capital for different time horizons; (2) the venture capitalists usually exit only partially at the IPO and commit themselves to hold part of their shares for several months beyond the IPO (lock-up) and (3) there are large differences in the level of these post-IPO shareholdings by venture capitalists. Our aim is to shed light on these issues. Within 
a single model, we analyze the venture capitalist's decision on the timing, the offer price and the fraction of shares he sells in the course of the IPO.

Venture capitalists offer a combined provision of capital and managerial experience (see e.g. Casamatta (2002) for a theoretical analysis or Kaplan and Strömberg (2001) for an empirical one). They monitor strategic and managerial decisions and tend to take an active role in advising the firm and providing it with valuable business contacts (e.g. with consultants, lawyers, investment bankers) or qualified staff. Based on US data, Hellmann and Puri (2002) found out that companies that obtain venture capital are more likely and/or quicker to become professional than their non venture-backed counterparts. In our model, we consider two periods and two types of firms (high- and low-quality). Each firm carries out a single project. The projects of high-quality firms differ in the role that the venture capitalist can play. The higher the consulting intensity of a project, the more the venture capitalist's managerial activities enhance the firm's value in the second period. If the project has a low consulting intensity, the venture capitalist's managerial contribution adds only little value in the second period.

As active investors, venture capitalists know the young firms which they finance better than the potential new investors. The timing and the extent of the IPO influences the new investors' assessment of the quality of the firm. The younger the firms are, the higher the information asymmetry is between the venture capitalist and the new investors. Here we assume that the venture capitalist knows the firm and project characteristics in $t=1$, with the NIs receiving the information in $t=2$. In $t=1$, the NIs only know the probability distributions over firm types and project kinds. Thus, if the venture capitalist takes a high-quality firm public in $t=1$, he may want to signal that the IPO is not a means of getting rid of low-quality stocks. Rather, he would like to demonstrate that his reason for selling the company is a low 
benefit of his managerial support because the project is not very consulting intensive. A costly obligation of not selling a part of his shares for a certain period of time (lock-up) can serve as such a signaling device.

Our paper is different from the existing theoretical research on venture capital and venture capitalist's exit, which typically deals with the choice of the optimal exit channel assuming (and analyzing) a conflict between the venture capitalist and the entrepreneur (see Berglöf, 1994 or Bascha and Walz, 2001). We do not consider this kind of conflict. Instead, our paper analyzes the information asymmetry between the old investor (the venture capitalist) and the potential new investors. We introduce a new aspect: the timing of the exit.

Our model points out the role of the value added by the venture capitalist. One of the differences between the venture capitalist and the new investors who buy the firm at the IPO is that the former offer not only money but also managerial support that enhances the value of the high-quality firm. Since the IPO reduces the venture capitalist's stake in the firm, incentives to be active in the management of the company are diminished after the IPO. The potential value added from the non-monetary contribution by the venture capitalist depends on the firm type (high- or low-quality) and the kind of project. For low-quality firms (in both periods) and for the projects with the lowest consulting intensity (in the second period), the potential value added from the non-monetary contribution is zero. In these cases, the venture capitalist wants to exit his firm as soon as possible, since binding his resources there is costly. However, the new investors who purchase shares from venture capitalists do not observe the quality of young firms and the kind of projects. In order to receive a higher price for his shares, the venture capitalist who owns a high-quality firm has to prove its quality. He must either finance his firm longer (until the firm gets older and the information asymmetries are mitigated), which might be too costly for projects with a low consulting intensity, or sig- 
nal the quality of the young firm going public. We will show under which conditions a separating equilibrium holds in which low-quality firms are liquidated and high-quality firms go public either after one period with a lock-up (lower consulting intensity) or after two periods without a lock-up (higher consulting intensity).

Considering the possibility of signaling through a lock-up, our paper contributes to the existing literature on the IPO and signaling (see Allen and Faulhaber, 1989, Grinblatt and Hwang, 1989 or Welch, 1989). A seminal paper on signaling as a means of information transfer between the informed entrepreneur and the uninformed new investors is Leland and Pyle (1977). They show that the entrepreneur's willingness to invest in his own project can serve as a signal of the project quality. In contrast to our model, the above-mentioned models deal with investors in general, instead of venture capitalists in particular. In our model, we try to capture the following three specific features of venture capitalists and venture-backed IPOs: (1) the combined provision of capital and management experience, (2) the superior information of venture capitalists on the companies they finance and (3) the limited investment horizon of venture capitalists. A paper related to ours that considers lock-up and venture capital is Neus and Walz (2002). They consider the timing of IPOs as given and ask whether or not the venture capitalists use a lock-up. In contrast, the central issue of the model we develop in the subsequent sections concerns the timing of the IPO.

The structure of the rest of the paper is as follows: section 2 will present the structure of the model, the analysis of the exit decision will be carried out in section 3, and, finally, section 4 will conclude and offer some empirically testable implications derived from the theoretical analysis. 


\section{Setup of the Model}

Our model consists of two periods, two types of firms (high- and lowquality) and infinitely many possible kinds of projects that differ in the role of the non-monetary contribution by the venture capitalist. Each venture capitalist (VC) finances completely a single firm from the start of the first period $(t=0)$. Each firm carries out a single project. The value of the firm depends on its type, kind of project and VC's monetary investment and non-monetary contribution. At the end of each period there are numerous new investors (NIs) who are interested in buying firms in public markets from the VCs. The issues we want to analyze are in which period a VC exits his investment and what divestment strategy he chooses. All VCs and NIs are risk neutral and rational investors.

Further, we assume that:

1. the parameters, functional forms, structure of the game and players' rationality are common knowledge among the players;

2. the venture capitalist chooses the strategy (timing, exit channel, price per share and number of shares sold at the IPO) that maximizes his profit given the known expectation formation by the NIs;

3. there are infinitely many new investors with identical and rational beliefs who in $t=1$ and $t=2$ are willing to pay a price per share that equals the share value they expect.

The VC can exit his investment either after one $(t=1)$ or after two $(t=2)$ periods. He may choose one of the following options: to liquidate the firm, sell the entire firm at the time of the IPO or disinvest sequentially (sell a part of his shares at the end of the first period and the rest at the end of the second). The $\mathrm{VC}$ cannot retain any shares beyond $t=2$ since his investment horizon is limited to a maximum of two periods. The time structure is the following (see Figure 1): in $t=0$ 
the firm is founded and the venture capital financing starts; in $t=1$ the nature determines the type of firm and the kind of project and the VC gets this information; then, he has to decide whether or not he will continue to finance the firm until $t=2$. With the exception of projects with the lowest consulting intensity, the VC's further monetary and non-monetary contribution in the second period increase the value of the H-firm (and, therefore, the price that NIs will be willing to pay). Before a new period starts (in $t=0, t=1$ and $t=2$ ), this growing firm needs a monetary investment $I$ (exogenously given) to finance its activities in the coming period. Without this investment the firm cannot survive. Prior to the IPO, these investments are financed by the VC as the sole investor. In the period that follows the IPO, the revenues raised for the new issue cover the investment demands of the expanding firm. After being listed, the firm gains access to the credit markets, which finance any further investments in later periods.

\section{Figure 1: The Time Structure of the Model}

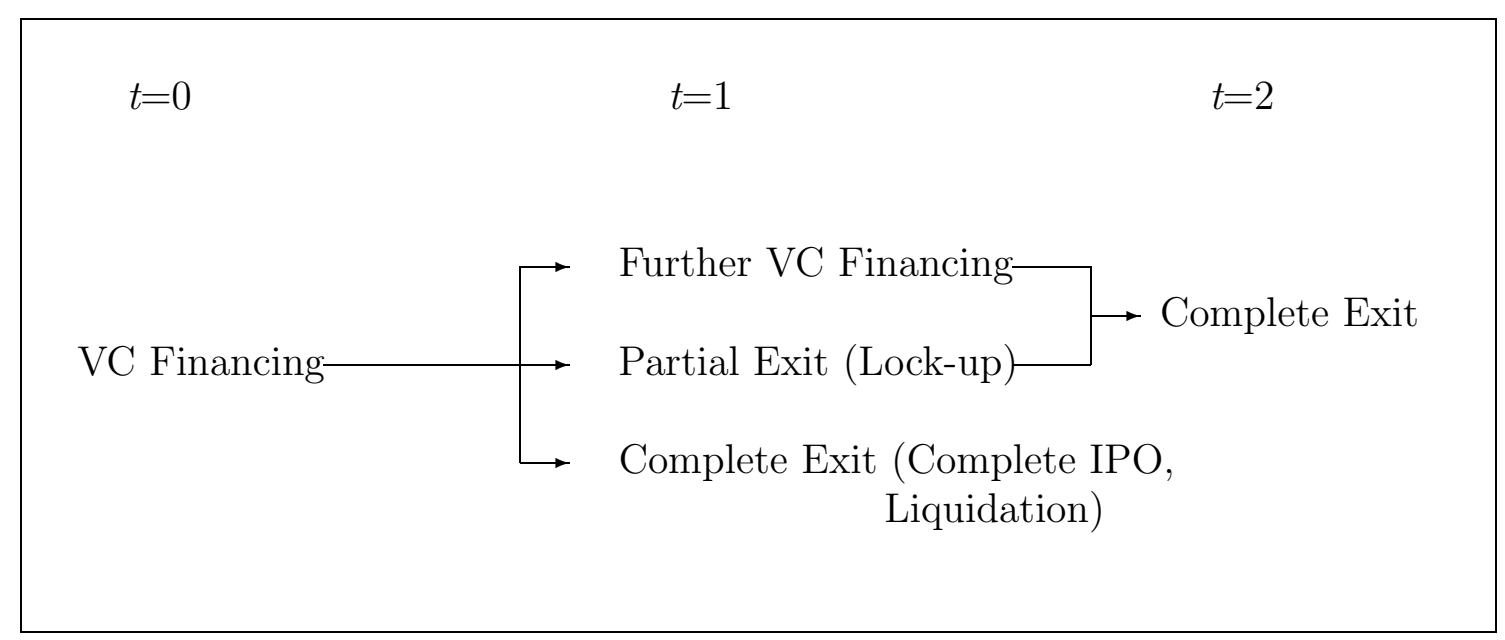

In $t=1$ the $\mathrm{VC}$ may decide not to spend further financial resources on the second period's financing, at which time he may either liquidate the firm or let other investors carry out the necessary investment by taking the firm public in $t=1$. In the latter case he has two options: to sell the firm completely (complete IPO) or to exit partially and retain 
some of his shares until $t=2$ (lock-up). Under conditions that will be specified later, the following separating equilibrium exists: low-quality firms are liquidated in $t=1$ and high-quality firms are sold either per partes in $t=1$ and $t=2$ (lock-up) or as a whole in $t=2$ depending on the kind of project and, hence, the role of the managerial contribution by the VC.

If the firm goes public in $t=1$, new shares are issued and the VC may sell some or all of his old shares. For simplicity, let the number of original shares (= before the IPO) be one. It is, however, possible to split this share. It is held solely by the $\mathrm{VC}$ since $t=0$. The number (and the fraction) of the original shares sold by the venture capitalist at the IPO is denoted by $a$ (no lock-up: $a=1$, lock-up: $0 \leq a<1$ ). The number of new shares issued (and bought by the NIs) is $d$. Thus, the total number of shares after the IPO is $1+d$.

A venture capitalist is actively involved in the company he finances. The higher the shareholdings of the venture capitalist in a period, the higher his administrative costs in this period. In the first period, when he holds the complete firm, the administrative cost equals $B$. In the second period, when he holds $(1-a)$ shares, the cost amounts to

$$
B \cdot(1-a) \text {. }
$$

When he does not sell any shares in $t=1$, the administrative cost of the $\mathrm{VC}$ in the second period is $B$. The more shares sold in $t=1$ (higher a), the lower the shareholdings and, obviously, the administrative cost of the $\mathrm{VC}$ in the second period.

Two types $\sigma$ of firms exist. The firms have either high or low quality $(\sigma \in\{H, L\})$ with equal probability in $t=0(\operatorname{Prob}(\sigma=H)=\operatorname{Prob}(\sigma=L)$ $=0.5)$. In $t=0$ neither the $\mathrm{VC}$ nor the NIs know the true type of firm; they only know the percentage of high-quality firms. Since the VC is deeply involved in firm activities he recognizes the type earlier than the potential NIs do. We assume that the VC knows the type of firm in $t=1$ and the NIs in $t=2$ when the firm grows older and more track record is available. 
At the IPO new and old shares are offered. The VC gets the revenues from selling the original shares since he has been their sole owner. The firm obtains the revenues from the new issue. We assume that the new issue exactly covers the investment demands of the firm in the period following the IPO. The number of new shares issued $d$ is then determined by the exogenously given investment demand $I$ and the share price $p($.$) that the \mathrm{VC}$ sets

$$
d=\frac{I}{p(.)} .
$$

In front of the IPO, the VC chooses the price $p($.$) he wants to re-$ ceive per share and the fraction $a$ of his shares he wants to sell and announces this information to the new investors. The number of new shares is determined through (2). The issue of how price is set by the venture capitalist will be explained later in this section. In the course of the IPO, any new investor may buy shares at this price. If the new shares were not sold, the investment demands of the firm could not be met and the firm would be liquidated. ${ }^{2}$ As the $\mathrm{VC}$ is rational and he maximizes his utility, this would never happen. The VC knows the expectation building of the NIs and, hence, the combination of price and number of shares they will accept. The VC would never spend the IPO costs and then let the IPO fail by choosing a non-acceptable combination of price and number of shares he offers. Liquidation would be the more profitable strategy for him.

The value of a firm depends on the firm's type. The value of an L-firm is always zero. Neither the monetary investment nor the non-monetary contribution of the VC can increase the value of the type L.

$$
W^{L}(t)=0 \quad t \in\{0,1,2\} .
$$

The VC invests exogenously given amounts $I$ (as a monetary investment) and $B$ (as a non-monetary contribution) in each period in which

\footnotetext{
${ }^{2}$ In our model, either all (announced fraction of old shares plus the new issue) or no offered shares are sold because infinitely many identical new investors exist. If the price is "reasonable", all offered shares are sold because the demand is infinite. If the price was "too high", nobody would buy any shares.
} 
he completely finances the firm. The value of an $\mathrm{H}$-firm depends on the sum of the monetary investments and the non-monetary contributions as well as the kind of project. The rate of return on the investment is $k-1(k>1)$.

Each firm carries out a single project. The projects of high-quality firms differ in their consulting intensity which is denoted by $r \in[0,1]$. The probability over the project kinds in $t=0$ is equally distributed on the interval $[0,1]$. The information structure here is the same as for the type of firm. In $t=1$ the $\mathrm{VC}$ can observe the kind of project that is being financed and, therefore, how large the potential value is which might be added to the firm by his further non-monetary contribution. The NIs cannot see this feature in $t=1$. They know only the probability distribution.

The higher the consulting intensity of a project (higher $r$ ) is, the more value adds the VC's non-monetary contribution in the second period. If a venture capitalist is present in an $\mathrm{H}$-firm, his non-monetary contribution adds value $k B$ in the first period. The VC's full engagement in the second period raises the value of the type $\mathrm{H}$ further by $r k B$. If a $\mathrm{VC}$ takes a firm public in $t=1$ and retains some or all of the original shares (lock-up), his fraction of the firm shrinks after the IPO. Therefore, his claim to actively manage the company is diluted and his incentives are diminished. For convenience, we assume that if the firm goes public in $t=1$ and the $\mathrm{VC}$ retains some shares until $t=2$, he no longer adds value to the company. He still has some administrative costs (see (1)) related to his presence in the firm, however. The costs and benefits from the VC's non-monetary contribution to an H-firm are summarized in Table 1. 
Table 1: The managerial contribution by the VC to an H-firm

\begin{tabular}{|r||c||c||c||}
\multicolumn{4}{|c|}{ (net benefits = benefits - costs; $k>1$ ) } \\
\hline Exit channel & $\begin{array}{c}\text { Complete IPO } \\
\text { in } t=1\end{array}$ & $\begin{array}{c}\text { Complete IPO } \\
\text { in } t=2\end{array}$ & Lock-up \\
\hline $\begin{array}{c}\text { First Period: } \\
\text { NET BENEFITS }\end{array}$ & $k B-B$ & $k B-B$ & $k B-B$ \\
\hline $\begin{array}{c}\text { Second Period: } \\
\text { NET BENEFITS }\end{array}$ & $0-0$ & $r k B-B$ & $0-B \cdot(1-a)$ \\
\hline
\end{tabular}

Every investment $I$ that is carried out either by the VC or by the NIs (through buying the new stock) increases the value of the H-firm by $k I$. The benefits from the non-monetary contribution of the venture capitalist raise the value of the firm additively. The value of an $\mathrm{H}-$ firm at the IPO is thus the sum of the benefits from the monetary investments by the venture capitalist (their number equals the number of pre-IPO periods $t$ in which the firm has been financed by venture capital), the benefits from the investment carried out by the NIs at the IPO and the benefits from the non-monetary contribution of the $\mathrm{VC}$ before the IPO. If the IPO is conducted in $t=1$, the value of an $\mathrm{H}$-firm is

$$
W^{H}(t \mid t=1)=k \cdot(2 I+B)
$$

If an H-firm is completely financed by the $\mathrm{VC}$ for two periods, its value at the end of the second period depends on the kind of project $r$ :

$$
W^{H r}(t \mid t=2)=k \cdot[3 I+(1+r) \cdot B] .
$$

We assume that there are infinitely many new investors who want to buy the new stock. The VC has all the bargaining power, which enables him to extract the entire surplus. The NIs do not know the value of the firm in $t=1$. The verification of the firm type and the project kind is impossible (i.e. very costly). We denote the value of 
the firm that the NIs expect after the IPO in $t$ by $E\left[W^{\sigma r}(t)\right]$. In $t=2$, the NIs have full information so that $E\left[W^{\sigma r}(t \mid t=2)\right]$ equals the true value, which is 0 for an L-firm (see (3)) and $k \cdot[3 I+(1+r) \cdot B]$ for an H-firm (see (5)).

After the IPO, the total number of shares consists of 1 old share plus $d$ new shares. The value of a share that the NIs expect during and after the IPO equals the expected value of the firm divided by the (known) number of shares

$$
\frac{E\left[W^{\sigma r}(t)\right]}{1+d}
$$

If $E\left[W^{\sigma r}(t)\right]<I$, the NIs do not buy any shares (see Appendix A for the proof.) The intuition is the following: if the NIs bought new shares and hence invested the amount of $I$, their investment would generate a negative net expected value due to the fact that after this investment, the expected value of the firm would be lower than the investment itself. Therefore, the NIs prefer to retain their funds and do not buy any shares. If $E\left[W^{\sigma r}(t)\right] \geq I$, the NIs are willing to pay the price of (6) per share. Combining (6) and (2) we get the maximum price per share $p\left(E\left[W^{\sigma r}(t)\right], I\right)$ that the NIs are willing to pay at the IPO

$$
p\left(E\left[W^{\sigma r}(t)\right], I\right)=\max \left\{E\left[W^{\sigma r}(t)\right]-I, 0\right\} .
$$

For this price, the VC may sell as many shares as he wants since there are infinitely many investors with identical beliefs. (However, the number of shares sold in $t=1$ influences the expectation building by the NIs.) If the venture capitalist were to set a higher price, the demand for shares would be 0 . If he were to set a lower price than the maximum price per share $p\left(E\left[W^{\sigma r}(t)\right], I\right)$ that the NIs were willing to pay, he would only diminish his own profit, which equals the revenue from selling the shares minus the cost. ${ }^{3}$ The issue of how NIs form their expectations in $t=1$ will be analyzed in the next section.

\footnotetext{
${ }^{3}$ In the lock-up case, a lower price at the IPO in $t=1$ would additionally lead to a dilution of the remaining VC's holdings and hence to a lower price per share and lower revenues in $t=2$ because more new shares had to be issued in $t=1$ in order to finance $I$.
} 
We will show that the choice of the price alone by the $\mathrm{VC}$ has no impact on expectation building by the NIs. The venture capitalist, as a profit maximizer and a sophisticated investor who understands the expectation building process of the NIs, sets the maximum possible price he can receive when he exits via IPO (complete IPO in $t=1$, complete IPO in $t=2$, lock-up). If the IPO takes place in $t=2$, the NIs are fully informed. Then, the share price of an L-firm in $t=2$ would be 0 , while the share price of an $\mathrm{H}$-firm at the IPO would reach $k \cdot(3 I+(1+r) \cdot B)-I$.

When lock-up is used, after the first period $a$ old shares are sold by the $\mathrm{VC}$ for the price $p\left(E\left[W^{\sigma}(t \mid t=1)\right], I\right)=\max \left\{E\left[W^{\sigma}(t \mid t=\right.\right.$ 1)] $-I, 0\} .{ }^{4}$ The rest of the shares $(1-a)$ is sold in $t=2$ for the price $p\left(E\left[W^{\sigma}(\right.\right.$ lock $\left.\left.)\right], I\right)$. Since there is full information in $t=2$, the maximum possible price that the NIs are willing to pay corresponds to the true value of the firm, which for type $\mathrm{H}$ equals $E\left[W^{\sigma}(t \mid t=1)\right]=$ $W^{H}(t \mid t=1)=k \cdot(2 I+B)$. Thus, the maximum price per share which the NIs are willing to pay in $t=2$ for the rest $(1-a)$ of the shares depends on the value of the firm and the number of shares issued in the first period (see (2) and (6)).

$$
p\left(E\left[W^{\sigma}(\text { lock })\right], I\right)= \begin{cases}\frac{p \cdot k \cdot(2 I+B)}{p+I} & \text { for an H-type, } \\ 0 & \text { for an L-type }\end{cases}
$$

where $p>0$ is the price per share in $t=1$.

If the VC completely finances the firm until $t \in\{1,2\}$, he finances t-times the investment $I$ and spends administrative costs of t-times $B$. The total VC's financing cost then amounts to $t \cdot(I+B)$. In the case of a lock-up, he spends $I+B(2-a)$ because he completely finances the first period causing costs of $I+B$, and he retains $(1-a)$ shares between $t=1$ and $t=2$ causing costs of $B(1-a)$. Further, there

\footnotetext{
${ }^{4}$ Obviously, the type of project does not play any role in the value of the firm in the case of a lock-up. In $t=1$ the NIs enter, and the VC's presence in the firm no longer increases the firm's value in the second period.
} 
are some negligible IPO costs of $\epsilon$ that make an IPO slightly more expensive than a liquidation (for every $\gamma \in R^{+}: 0<\epsilon<\gamma$ ). The consequence is that if the maximum possible price the $\mathrm{VC}$ can get at the IPO in $t$ is zero, he prefers liquidation in $t$.

The VC chooses that exit strategy which maximizes his profit. We have already argued why he chooses the maximum possible price he can receive. Under different exit channels, the $\mathrm{VC}$ then reaches the following levels of profit:

1. Since there are no revenues in the case of liquidation, the profit $\pi_{l i q}^{\sigma}(t)$ of the $\mathrm{VC}$ who liquidates a firm in $t \in\{1,2\}$ will be the negative sum of the monetary and non-monetary expenditures

$$
\pi_{l i q}^{\sigma}(t)=\pi_{l i q}^{H}(t)=\pi_{l i q}^{L}(t)=-t \cdot(I+B) .
$$

2. If an IPO takes place in $t \in\{1,2\}$, the profit of the $\mathrm{VC}$ amounts to the difference between the revenues from the IPO and the costs.

- Without a lock-up (complete IPO) the profit is

$$
\pi_{i p o}^{\sigma r}(t)=E\left[W^{\sigma r}(t)\right]-(t+1) \cdot I-t \cdot B-\epsilon,
$$

- with a lock-up (partial IPO) the profit reaches

$$
\begin{aligned}
\pi_{\text {lock }}^{\sigma} & =a \cdot p\left(E\left[W^{\sigma}(t \mid t=1)\right]\right)+(1-a) \cdot p\left(E\left[W^{\sigma}(\text { lock })\right], I\right) \\
& -I-(2-a) B-\epsilon .
\end{aligned}
$$

In the next section we show, that under certain assumptions about the parameters of the model a single equilibrium exists, in which highquality firms separate from low-quality firms. The latter are liquidated after the first period. The former go public either after having been financed by venture capital for two periods or after one financing period using a lock-up. The VC's decision between one or two periods depends on the kind of project. For firms with less consulting intensive projects, for which the managerial contribution of the $\mathrm{VC}$ in the second period adds only a low value, the lock-up serves as a signaling device to indicate high quality. 


\section{Exit Decision}

\subsection{Information Symmetry}

In order to demonstrate how the model is designed and to get a benchmark for the more realistic case of information asymmetry, we first consider the case of symmetric information. Under symmetric information everybody already knows the type of firm in $t=1$. Hence, the new investors' expectations in $t=1$ are the following:

$$
E\left[W^{\sigma}(t \mid t=1)\right]=\left\{\begin{array}{lr}
W^{H}(t \mid t=1)=k \cdot(2 I+B) & \text { for an H-type } \\
W^{L}(t \mid t=1)=0 & \text { for an L-type. }
\end{array}\right.
$$

\section{Proposition 1 (SYMMETRIC INFORMATION):}

Let $\bar{k}:=\frac{B+I}{I}$ and $r^{*}:=\frac{B+I-k I}{k B}\left(r^{*} \in(0,1)\right)$. We assume that $k<\bar{k}^{5}$ If everybody knows the firm type in $t=1$, then a type $L$ will be liquidated in $t=1$ and a type $H$ will go public in either $t=1$ (for $r \leq r^{*}$ ) or in $t=2\left(\right.$ for $\left.r>r^{*}\right)$. The VC sells all his shares at the IPO (no lock-up). The price per share in $t=1$ equals $k \cdot(2 I+B)-I$, the price per share in $t=2$ is $k \cdot[3 I+(1+r) \cdot B]-I$.

\section{Proof}

\section{L-type}

The liquidation of an L-firm in $t=1$ is the profit maximizing strategy for the $\mathrm{VC}$ (with the profit $\pi_{\text {liq }}^{L}(t \mid t=1)=-I-B$ ). The reason is that since the NIs know that the type of the firm is L (and its value equals 0 ), they never pay a positive price for its shares. Thus, no other strategy would generate higher profits (in this case a lower loss) for the VC than liquidation in $t=1$ (see Appendix B): Further financing in the

\footnotetext{
${ }^{5}$ The other case $\frac{B+I}{I} \leq k$ is not interesting because in this case all H-firms would be held by the $\mathrm{VC}$ until $t=2$ due to the high rate of return.
} 
second period generates additional costs of $I+B$ and no revenues and, therefore, will not be chosen by the VC. The lock-up is not possible since the NIs would not finance the necessary investment $I$ in $t=1$ (because $\left.E\left[W^{\sigma}(t \mid t=1)\right]=W^{L}(t \mid t=1)=0<I\right)$. The complete IPO in $t=1$ generates no revenues compared to the liquidation but causes additionally IPO costs of $\epsilon$. Hence, liquidation in $t=1$ is the profit maximizing strategy.

\section{H-type}

The $\mathrm{VC}$ who finances an H-firm can earn profits by selling his shares. If the IPO takes place in $t=1$ (when $E\left[W^{\sigma}(t \mid t=1)\right]=W^{H}(t \mid t=1)=$ $k \cdot(2 I+B)$ ), the profit of the $\mathrm{VC}$ is equal to (see (7) and (10))

$$
\pi_{i p o}^{H}(t \mid t=1)=(k-1) \cdot(2 I+B)-\epsilon .
$$

If the IPO takes place in $t=2\left(\right.$ when $\left.E\left[W^{\sigma r}(t \mid t=2)\right]=W^{H r}(t \mid t=2)\right)$, the profit of the VC amounts to (see (5), (7), and (10))

$$
\pi_{i p o}^{H r}(t \mid t=2)=k \cdot[3 I+(1+r) \cdot B]-3 I-2 B-\epsilon .
$$

The VC prefers to sell all his shares at the IPO since his profit from the lock-up would only be $(k-1) \cdot(2 I+B)-B \cdot(1-a)-\epsilon$ (see Appendix $\mathrm{C}$ ), which is less than the profit from the complete IPO in $t=1$ (see (12)). Lock-up generates no additional revenues but raises additional costs of $B \cdot(1-a)$ for the venture capitalist's involvement in the second period. The VC takes a firm with $r \leq r^{*}$ in $t=1$ public and a firm with $r>r^{*}$ in $t=2$. The profit levels are $\pi_{i p o}^{H}(t \mid t=1)(\operatorname{see}(12))$ for the former and $\pi_{i p o}^{H r}(t \mid t=2)$ (see(13)) for the latter case. Whether or not the NIs already know the kind of project in $t=1$ does not affect the result.

\subsection{Information Asymmetry}

We next consider a more relevant distribution of information where the $\mathrm{VC}$, as an active investor, has an information advantage over the 
NIs. He knows the type of firm and the kind of project he finances earlier than the NIs. In $t=0$ nobody knows the value of either of the two parameters. We assume that if the firm has been financed by the $\mathrm{VC}$ only for one period $(t=1)$, the NIs recognize neither its type nor the kind of project at the time of the IPO. At this time they know only the probability distribution over the two firm types and the kinds of projects. The $\mathrm{VC}$ knows the value of both of these parameters in $t=1$. The information advantage of the $\mathrm{VC}$ disappears in $t=2$ when the NIs can observe the true value of the firm.

In what follows, we investigate the decision of the profit maximizing $\mathrm{VC}$ in $t=1$ for an L-firm and an H-firm with different kinds of projects. Under certain assumptions, which will be analyzed here, a unique (separating) equilibrium exists.

\section{Proposition 2 (ASYMMETRIC INFORMATION - H-firm with $\left.r>r^{*}\right)$ : \\ If $r>r^{*}$, then an H-firm goes public in $t=2$ and the $V C$ sells the whole firm at the IPO. The price per share is $k \cdot[3 I+(1+r) \cdot B]-I$.}

\section{Proof}

If the project for which $r>r^{*}$ is sold in $t=2$ for the maximum possible price, the profit of the $\mathrm{VC}$ is $k \cdot[3 I+(1+r) \cdot B]-3 I-2 B-\epsilon$. This is exactly the same profit as in the information symmetry case (see section 3.1), since in $t=2$ the information asymmetries between the $\mathrm{VC}$ and the NIs are dissolved. Under information asymmetry, none of the other exit channels (an IPO in $t=1$ with or without a lock-up or liquidation) can generate higher profits than in the case of the symmetric information. The reason is that in all these cases the costs remain unchanged while in neither case the revenues can be increased. If the $\mathrm{VC}$ were to choose a higher price per share, no shares would be sold. If the price were lower, the profit would shrink. Therefore, 
under asymmetric information in $t=1$, the $\mathrm{VC}$ takes a type $\mathrm{H}$ who has a project with $r>r^{*}$ in $t=2$ public for the price per share of $k \cdot[3 I+(1+r) \cdot B]-I$. He chooses the same strategy as in the reference case of information symmetry.

Let us now analyze which strategy is chosen by the VC for an L-firm and for an H-firm that has a less consulting intensive project $(r \leq$ $\left.r^{*}\right)$. Financing this project, the $\mathrm{VC}$ has low comparative advantage against the NIs in raising the firm's value in the second period. Due to administrative costs, a type $\mathrm{H}$ with such a project goes public in $t=1$ under information symmetry. Type $\mathrm{L}$ is liquidated in $t=1$. If there is asymmetric information, observing a complete IPO in $t=1$, the NIs cannot distinguish between an H-firm and an L-firm. The VC who finances a type $\mathrm{L}$ prefers a complete IPO in $t=1$ to a liquidation whenever he can get a share price which is higher than the IPO costs $\epsilon$. The maximum price that the NIs are willing to pay when a complete IPO takes place in $t=1$ may be "too low" for an H-firm. Waiting until the information asymmetries are resolved or selling only a part of his shares in $t=1$ may be more profitable for the VC. In order to determine the price that the NIs will be willing to pay in $t=1$, we have to analyze the NIs' expectation building. To do this, we have to look at the VC's payoffs from different strategies under asymmetric information and find out the profit maximizing strategy.

Each firm has five possible exit channels: IPO in $t=1$ with a lock-up, IPO in $t=1$ without a lock-up, IPO in $t=2$, liquidation in $t=1$ and liquidation in $t=2$. Obviously, liquidation in any period is strictly dominated by the IPO in $t=2$ for an H-firm. Thus, an H-firm goes public. For an L-firm, further venture capital financing in the second period (an IPO or a liquidation in $t=2$ ) is strictly dominated by the liquidation in $t=1$. After the elimination of these strictly dominated strategies of both types, we have three exit channels for each type to be considered. 
The following three aspects of the IPO process can be distinguished: (1) the timing $(t=1$ or $t=2)$, (2) the quantity of shares sold at the time of IPO $(a=1$ or $a<1)$ and (3) the price per share $p($.$) . If we$ assume that a firm goes public in $t=1$ and that the VC offers all of his shares at the IPO $(a=1)$, then we have already determined the first two of the three characteristics. In this case, there is no possibility for $\mathrm{H}$ to separate from $\mathrm{L}$. The reason is that any price higher than $\epsilon$ that the VC demands for a type $\mathrm{H}$ in $t=1$ would result in an IPO of an L-firm in $t=1$ as well. A price per share lower than $\epsilon$ that would prevent an L-firm from the IPO will not be chosen by an H-firm since this strategy for him is strictly dominated by the IPO in $t=2$.

Assuming that both types may participate in the IPO in $t=1$, the NIs would expect a firm's value $E\left[W^{\sigma}(t \mid t=1)\right]_{\text {pool }}$ that is not higher than the average firm's value over both types of firm in $t=1$.

$$
\begin{aligned}
E\left[W^{\sigma}(t \mid t=1)\right]_{\text {pool }} & \leq \operatorname{Prob}(\sigma=H) \cdot W^{H}(t \mid t=1) \\
& +\operatorname{Prob}(\sigma=L) \cdot W^{L}= \\
& =\frac{k \cdot(2 I+B)}{2} .
\end{aligned}
$$

The maximum possible pooling price per share would then be $\max \left\{\frac{k \cdot(2 I+B)}{2}-I, 0\right\}$. If the $\mathrm{VC}$ demanded a higher price for a complete IPO, NIs would not buy any shares. Hence, the profit of the VC who would sell a type $\mathrm{H}$ in $t=1$ via IPO without a lock-up would be not higher than $\max \left\{\frac{k \cdot(2 I+B)}{2}-2 I-B-\epsilon,-I-B-\epsilon\right\}$.

\section{Proposition 3 (ASYMMETRIC INFORMATION - optimal} lock-up strategy): Let us assume that a profit maximizing $V C$ finances an H-firm. If he prefers the lock-up to the complete IPO, then he sets the share price at $p^{*}=k \cdot(2 I+B)-I$, and he sells a fraction $a^{*}=\frac{B}{k(2 I+B)-I+B}$ of old shares in $t=1$. 


\section{Proof}

Under $p^{*}$ and $a^{*}$, a $\mathrm{VC}$ who finances an L-firm prefers liquidation in $t=1$ to the lock-up in $t=1$ (see Appendix D). Therefore, if $a=a^{*}$, the new investors are willing to pay the price $p^{*}$ per share that corresponds to the value of an H-type. Now we will show that a profit maximizing VC would not choose another lock-up strategy (by setting other levels of $p$ and/or $a<1$ ).

If the $\mathrm{VC}$ with an $\mathrm{H}$-firm chose in $t=1$ a price $\bar{p}$ that was higher than $p^{*}$, no NI would buy any shares in $t=1$ because the price would be higher than the firm value. The investment demand of the growing firm would not be met, and the firm would not survive. The VC would earn no revenues and, hence, his profit would be lower than if he chose $a^{*}$ and $p^{*}$. If the $\mathrm{VC}$ chose the same price per share $p^{*}$ and would offer a lower fraction of shares $a\left(a<a^{*}\right)$ in $t=1$, his profit would be lower due to higher costs of the non-monetary contribution, which are decreasing in $a$. If he chose a higher $a \in\left(a^{*}, 1\right)$, the $\mathrm{VC}$ who finances a type $\mathrm{L}$ would be interested in the lock-up as well. Thus, the NIs would not be willing to pay $p^{*}$.

If the $\mathrm{VC}$ opted in $t=1$ for a price per share $\widetilde{p}$ that was lower than $p^{*}$, he would have to issue more new shares in $t=1$ than under $p^{*}$ in order to finance the investment demands $I$ of the young firm in the second period. Since the value of the firm would remain the same but more new shares would be issued in $t=1$, the maximum possible share price the $\mathrm{VC}$ could get in $t=2$ for the rest of his shares would be lower than under $p^{*}$ and $a^{*}$. If the VC chose $\widetilde{p}$ and $a \in\left[0, \frac{B}{\tilde{p}+B}\right]$, an H-firm would separate from an L-firm. The VC's profit would be lower than the profit under $p^{*}$ and $a^{*}$ (see Appendix E). If $a \in\left(\frac{B}{\tilde{p}+B}, 1\right)$, an L-firm would be interested in the lock-up as well, and we would have a situation with pooling that, for the H-firm, is strictly dominated either by lock-up with $p^{*}$ and $a^{*}$ or by the complete IPO in $t=1$ (see Appendix E). Therefore, if the profit maximizing $\mathrm{VC}$ with a type $\mathrm{H}$ prefers a lock-up to a complete IPO, his strategy will be to 
sell a fraction $a^{*}=\frac{B}{k(2 I+B)-I+B}$ of old shares in $t=1$ for the price per share of $p^{*}=k \cdot(2 I+B)-I$.

We next explore whether the lock-up with $a^{*}$ and $p^{*}$ may be an equilibrium strategy for the type $\mathrm{H}$ with $r \leq r^{*}$ (and if liquidation in $t=1$ may be an equilibrium strategy for the type L) or if other exit channels may generate higher profits.

\section{Proposition 4 (ASYMMETRIC INFORMATION - separat- ing equilibrium):}

Let us assume that the following condition holds:

$k<\left(I+B \cdot \frac{B}{k(2 I+B)-I+B}\right) / I$. Let $r^{* *}:=\frac{a^{*} B+I-k I}{k B}$.

Then, a separating equilibrium will emerge in which an L-firm is liquidated in $t=1$, an $H$-firm with $r>r^{* *}$ goes public in $t=2$ for a price per share of $k \cdot[3 I+(1+r) \cdot B]-I$ and, finally, an H-firm with $r \leq r^{* *}$ goes public in $t=1$ for a share price of $p^{*}=k \cdot(2 I+B)-I$. The fraction of old shares the VC sells at the IPO in $t=1$ is $a^{*}=\frac{B}{k(2 I+B)-I+B}$ (lock-up).

\section{Proof}

If the $\mathrm{VC}$ finances an $\mathrm{H}$-firm, the complete IPO in $t=1$ is dominated by the lock-up with $a^{*}$ and $p^{*}$ for all kinds of projects (see Appendix F). When $r>r^{* *}$, the VC prefers an IPO in $t=2$ to the lock-up. When $r \leq r^{* *}$, the VC favors a lock-up with $a^{*}$ and $p^{*}$ to an IPO in $t=2$ (see Appendix F). Thus, for the $\mathrm{VC}$ with a type $\mathrm{H}$ and $r \leq r^{* *}$, lock-up with $a^{*}$ and $p^{*}$ strictly dominates other strategies (see Proposition $3)$. The NIs know this and would indicate any other pair $\left(p \neq p^{*}\right.$ and $\left.a \neq a^{*}\right)$ as an action by an L-firm. The consequence is that the price per share they would be willing to pay in $t=1$ if $a \neq a^{*}$ would equal 0 . Hence, due to the IPO costs, the IPO in $t=1$ is strictly dominated 
by the liquidation in $t=1$ for an L-firm.

Under information asymmetry, VCs have to prove the quality of the firms they finance. This is costly and leads to inefficiencies. Compared to the situation with symmetric information, more firms are financed for two periods $\left(r^{* *}<r^{*}\right)$. Firms which are taken public after the first period are sold only partially at the IPO. The lock-up serves as a signaling device.

\subsection{Comparative Statics}

We next look at some comparative statics results concerning the existence of the equilibrium and its features. If the condition (see Proposition 4) $k<\left(I+B \cdot \frac{B}{k(2 I+B)-I+B}\right) / I$ holds, we have a separating equilibrium described in section 3.2 where high-quality firms go public in $t=1$ or $t=2$ (depending on the kind of project) and low-quality firms are liquidated in $t=1$. If this condition does not hold, waiting until $t=2$ is more profitable for all H-firms than any lock-up strategy. Thus, if $\left(I+B \cdot \frac{B}{k(2 I+B)-I+B}\right) / I$ were lower than $k$, another separating equilibrium would emerge in which all high-quality firms would go public in $t=2$ and low-quality firms would be liquidated in $t=1$.

Now we will concentrate on the features of the separating equilibrium with lock-up discussed in section 3.2, particularly on the fraction of IPOs at the end of the first period, the number of old shares sold at the IPO by the VCs (extent of a lock-up) and the share price.

\section{Proposition 5 (ASYMMETRIC INFORMATION - compar- ative statics)}

- Amount of the non-monetary contribution: The higher the amount of the non-monetary contribution $\boldsymbol{B}$ by the venture capitalist is, (i) the more firms go public after having been financed by venture capital only for one period, (ii) the higher is the fraction 
of old shares sold by the VC in $t=1$ and (iii) the higher are the share prices.

- Investment demands (size): The higher the investment demands $\boldsymbol{I}$ of the firm are, (i) the more firms go public after having been financed by venture capital for two periods, (ii) the lower is the fraction sold by the $V C$ in $t=1$ and (iii) the higher are the share prices.

- Rate of return: The higher the rate of return to the investment $(\boldsymbol{k}-\mathbf{1})$ is, (i) the more firms go public after having been financed by venture capital for two periods, (ii) the lower is the fraction sold by the VC in $t=1$ and (iii) the higher are the share prices.

\section{Proof}

See Appendix G.

\section{Conclusion}

After a certain period of time, venture capitalists have to exit their investments. The purpose of this paper has been to examine some important aspects of the divestment process of venture capitalists. Hereby, we have concentrated on the IPO as the most important exit channel and have analyzed how the timing of the IPO is chosen by the venture capitalists. Particularly we have offered answers on the following questions: (1) when do venture capitalists publicly offer their portfolio firms, (2) under which circumstances do they retain some shares beyond the IPO, (3) how large is the fraction of the retained shares and (4) how the share price is determined.

The difference between the venture capitalist and the new investors who buy shares at the IPO is that the former offers not only money but also managerial support that may enhance the value of the firm. This non-monetary contribution is lost after the IPO. The higher the 
consulting intensity of a project is, the more the venture capitalist's support raises the value of the firm, and, therefore, increases the venture capitalist's revenues when selling the firm. When deciding about the timing of the IPO, the venture capitalist compares his future benefits from his managerial and financial support with the future costs of spending his money and effort on his involvement in the firm. Another difference between the two types of investors is that the venture capitalist, being an active investor, is informed earlier about the value of the firm he has been financing than the potential new investors. Hence, the VC who finances a high-quality firm profits from the mitigation of the information asymmetry when the IPO takes place later. We have analyzed the VC's decision within a single model. It has consisted of two periods and two types of firms (high- and low-quality) with different kinds of projects. At the end of the second period the VC has not been allowed to retain any shares. We have considered the following five possible exit channels: (1) a complete IPO after the first period ( = the VC sells all his shares), (2) an IPO after the first period with a lock-up ( = the $\mathrm{VC}$ commits himself to retain some of his shares until the end of the second period), (3) a complete IPO after the second period, (4) a liquidation after the first period and (5) a liquidation after the second period. We have questioned the sort and features of exit emerging under the different firm and project characteristics.

An important issue of our model has been the venture capitalist's option to retain some shares beyond the IPO (lock-up). We have analyzed under which circumstances the venture capitalist uses this option and how large the fraction of the retained shares is. Our main finding has been that the venture capitalist holds some shares in order to signal to the new investors that the firm is of high quality. The signaling mechanism is the following: At the end of the second period when the remaining shares are to be sold, the new investors can observe the quality of the firm. If the quality is low, they do not buy any 
shares in $t=2$. In this case, the venture capitalist has raised revenues only at the IPO in $t=1$. Beyond a certain level of retained shares, low-quality firms are not interested in the lock-up since the revenues from the partial IPO in $t=1$ are not higher than the IPO expenses plus the costs spent in the second period. Thus, a liquidation in $t=1$ is more profitable than a lock-up for low-quality firms.

Expecting NIs' rational behavior, the venture capitalist maximizes his profit which equals the revenues from selling the shares minus the cost. After the elimination of the strictly dominated strategies, the following (separating) equilibrium emerges: High-quality firms with less consulting intensive projects use a lock-up and the VC sells a fraction of his shares in $t=1$ for the price per share that equals the share value in $t=1$. High-quality firms with more consulting intensive projects go public in $t=2$ at the share price that equals the share value in $t=2$. Low-quality firms are liquidated in $t=1$.

Our model provides a number of empirically testable implications:

- Firms with more consulting intensive projects will be financed longer by venture capital than firms with less consulting intensive projects. This finding could, for example, help explain differing lengths of financing periods in different industries.

- The high quality of young firms with a short venture capital financing period will be signaled through a lock-up. Since lock-up is a typical feature of almost every IPO in the US and most European markets, the fact that it is used will in practice have no signaling function. Further more, the length and the extent of the lock-up can be considered the signaling device.

- After the expiration of the lock-up period, the information asymmetry between the venture capitalist and the new investors is resolved. Thus, we can conclude a prediction concerning the length of the lock-up period: the higher the opacity of the firm and the greater the uncertainty, the longer the contracted lock-up period. 
- Over time, VCs' costs, investment demands and profitability of young firms may vary, for example due to some changes in the macroeconomic environment. Then, the fraction of firms that are financed by VCs over only a short time horizon (before they go public), should change. When the firm profitability and/or their investment demands increase, the fraction of the short-term financing should decrease. When the demands for the consulting by the VCs and, thus, the VCs' costs rise, the fraction of the short-term financing goes up.

The extent of the lock-up (fraction of shares retained by the venture capitalist) and the share price depend on the characteristics of the firm.

- The higher the extent of the non-monetary contribution by the venture capitalists, the lower the fraction of shares retained and the higher the price per share.

- The higher the investment demands (size) of the firm and/or the greater the profitability, the lower the fraction sold in $t=1$ and the higher the price per share.

\section{References}

Allen, F. and G. R. Faulhaber (1989): Signaling by Underpricing in the IPO Market, Journal of Financial Economics 23, 303-323.

BARry, C. B. (1994): New Directions in Research on Venture Capital Finance, Financial Management 23(3), 3-15. 
Bascha, A. and U. Walz (2001): Convertible Securities and Optimal Exit Decisions in Venture Capital Finance, Journal of Corporate Finance 7(3), 285-306.

Berglöf, E. (1994): A Control Theory of Venture Capital Finance, The Journal of Law, Economics and Organization 10(2), 247-267.

Black, B. S. and R. J. Gilson (1998): Venture Capital and the Structure of Capital Markets: Banks versus Stockmarkets, Journal of Financial Economics 47, 243-277.

Bygrave, W. and J. Timmons (1992): Venture Capital at the Crossroads. Harvard Business School Press, Boston, MA.

Casamatta, C. (2002): Financing and Advising: Optimal Financial Contracts with Venture Capitalists, discussion paper 3475, CEPR.

Gompers, P. A. (1998): Venture Capital Growing Pains: Should the Market Diet?, Journal of Banking and Finance 22, 1089-1104.

Grinblatt, M. and C. Y. Hwang (1989): Signaling and the Pricing of New Issues, The Journal of Finance 44(2), 393-420.

Hellmann, T. and M. Puri (2002): Venture Capital and the Professionalization of Start-Up Firms: Empirical Evidence, Journal of Finance 57, 169-197.

Jeng, L. A. and P. C. Wells (2000): The Determinants of Venture Capital Funding: Evidence Across Countries, Journal of Corporate Finance 6, 241-289.

Kaplan, S. N. and P. Strömberg (2001): Venture Capitalists as Principals: Contracting, Screening, and Monitoring, American Economic Review 91(2), 426-431.

Leland, H. E. and D. H. Pyle (1977): Information Asymmetries, Financial Structure, and Financial Intermediation, The Journal of Finance 32(2), 371-387. 
Neus, W. and U. Walz (2002): Exit Timing of Venture Capitalists in the Course of an Initial Public Offering, working paper 2002/07, CFS.

OECD (2002): Risk Capital in OECD Countries: Recent Development and Structural Issues, Financial Market Trends 82, 59-103.

Sahlman, W. A. (1990): The Structure and Governance of Venture Capital Organizations, Journal of Financial Economics 27, 473521.

Welch, I. (1989): Seasoned Offerings, Imitation Costs, and the Underpricing of Initial Public Offerings, The Journal of Finance 44(2), 421-449.

\section{Appendix A}

\section{The NIs' Participation in an IPO}

Using a proof by contradiction, we will show that if $E\left[W^{\sigma r}(t)\right]<I$, it is not profitable for the NIs to invest in the firm and finance the necessary investment $I$.

The value of a share that the NIs expect during and after the IPO (and, hence, the maximum price they are wiling to pay per share) equals the expected value of the firm divided by the known number of shares: $\frac{E\left[W^{\sigma r}(t)\right]}{1+d}$, where $d=I / p($.$) . Let us assume that E\left[W^{\sigma r}(t)\right]<I$, and, further, that the NIs buy shares and finance $I>0$ (which implies $p()>0$.$) . Then the maximum price p($.$) that the NIs are willing to$ pay is:

$p()=.\frac{E\left[W^{\sigma r}(t)\right]}{1+d}<\frac{I}{1+d}=\frac{p(.) I}{p(.)+I}$.

This implies: $p()+I<$.$I , hence p()<$.0 . This, however, contradicts the assumption that NIs buy shares and finance $I>0(p()>0$.$) .$ 


\section{Appendix B}

\section{Type L: Decision Under Information Symmetry}

The VC's profit from different exit strategies when financing an L-firm:

Liquidation in $t=1: \quad \pi_{l i q}^{L}(t \mid t=1)=-I-B$

Liquidation in $t=2: \quad \pi_{l i q}^{L}(t \mid t=2)=-2 I-2 B$

The price per share at the IPO is determined by (7).

$p()=.\max \left\{E\left[W^{L}(t)\right]-I, 0\right\}=\max \{-I, 0\}=0 \quad$ for $t \in\{1,2\}$

Complete IPO in $t=1: \quad \pi_{i p o}^{L}(t \mid t=1)=p()-I-B-.\epsilon=-I-B-\epsilon$

Complete IPO in $t=2: \quad \pi_{\text {ipo }}^{L}(t \mid t=2)=p()-.2 I-2 B-\epsilon=$ $=-2 I-2 B-\epsilon$

A liquidation in $t=1$ is the most favorable decision because it causes the least possible amount of loss.

\section{Appendix $\mathrm{C}$}

\section{Type H: Decision Under Information Symmetry}

The VC's profit when financing an H-firm:

Liquidation in $t=1: \quad \pi_{l i q}^{H}(t \mid t=1)=-I-B$

Liquidation in $t=2: \quad \pi_{l i q}^{H}(t \mid t=2)=-2 I-2 B$

Let us consider the IPO. The VC maximizes his profit and therefore chooses the highest possible price per share that the NIs are willing to pay. This equals the true value of the share (see (7)). 


$$
\begin{aligned}
p\left(E\left[W^{\sigma}(t \mid t=1)\right], I\right) & =\max \left\{W^{H}(t \mid t=1)-I, 0\right\}=k \cdot(2 I+B)-I \\
p\left(E\left[W^{\sigma r}(t \mid t=2)\right], I\right) & =\max \left\{W^{H r}(t \mid t=2)-I, 0\right\} \\
& =k \cdot[3 I+(1+r) \cdot B]-I
\end{aligned}
$$

The profits are:

IPO in $t=1$ :

$\pi_{i p o}^{H}(t \mid t=1)=p\left(E\left[W^{\sigma}(t \mid t=1)\right], I\right)-I-B-\epsilon==(k-1) \cdot(2 I+B)-\epsilon$

IPO in $t=2$ :

$$
\begin{aligned}
\pi_{i p o}^{H r}(t \mid t=2) & =p\left(E\left[W^{\sigma r}(t \mid t=2)\right], I\right)-2 I-2 B-\epsilon= \\
& =k \cdot[3 I+(1+r) \cdot B]-3 I-2 B-\epsilon
\end{aligned}
$$

In the case of a lock-up, the highest possible price per share in $t=1$ and $t=2$ is $p\left(E\left[W^{\sigma}(t \mid t=1)\right], I\right)=k \cdot(2 I+B)-I$ (see(8)). The VC's profit using a lock-up:

$$
\begin{aligned}
\pi_{\text {lock }}^{H} & =p\left(E\left[W^{\sigma}(t \mid t=1)\right], I\right)-I-B(2-a)-\epsilon= \\
& =k \cdot(2 I+B)-2 I-2 B+B a-\epsilon .
\end{aligned}
$$

The liquidation and the lock-up generate lower profits than a complete IPO in $t=1$. The choice between a complete IPO in $t=1$ and a complete IPO in $t=2$ depends on the kind of project.

$\pi_{i p o}^{H r}(t \mid t=2)>\pi_{i p o}^{H}(t \mid t=1) \Leftrightarrow k I-I+k r B-B>0 \Leftrightarrow r>\frac{B+I-k I}{k B}=$ $r^{*}$. Since $k<\frac{B+I}{I}, r^{*}>0$. Because $B-I(k-1)<k B, r^{*}<1$. For $r \leq r^{*}$, IPO in $t=1$ is more profitable than IPO in $t=2$. For $r>r^{*}$, IPO in $\mathrm{t}=2$ is more profitable than IPO in $t=1$. 


\section{Appendix D}

\section{Type L: Mimicking the H-firm vs. Liquidation Under Asym- metry}

The $\mathrm{VC}$ with a type $\mathrm{H}$ chooses the price per share $p^{*}=k \cdot(2 I+$ $B)-I$ in $t=1$ and the number of shares he sells at the IPO $a^{*}=$ $\frac{B}{k(2 I+B)-I+B}$. If a type $\mathrm{L}$ went public in $t=1$ accepting the same conditions and trying to mimic an $\mathrm{H}$-firm, the $\mathrm{VC}$ would get the price $p^{*}$ per share for $a^{*}$ shares. In $t=2$, the NIs would recognize the type of firm. Thus, the price per share would be $p_{\text {lock }}^{L}=0$ in $t=2$. In the sum, the $\mathrm{VC}$ would have spent $I$ on the monetary investment, $B\left(2-a^{*}\right)$ on the administrative costs and $\epsilon$ on the IPO expenses. The profit of the $\mathrm{VC}$ would reach:

$\pi_{l o c k}^{L}=a^{*} \cdot p^{*}-I-B\left(2-a^{*}\right)-\epsilon=-I-B-\epsilon<\pi_{\text {liq }}^{L}(t \mid t=1)$.

A lock-up would be less profitable than a liquidation for an L-type firm.

\section{Appendix E}

\section{Type H: The Choice of the Optimal Lock-up Strategy}

The profit $\pi_{\text {lock }}^{H}$ amounts under $p^{*}$ and $a^{*}$ to

$$
(k-1) \cdot(2 I+B)-B-\epsilon+B \cdot \frac{B}{k \cdot(2 I+B)-I+B} .
$$

Let us notice that, after a partial IPO in $t=1$, the maximum possible share price for an H-firm in $t=2$ (see (8)) is an increasing function of the first period's share price $p$ :

$\frac{d \frac{\mathbf{p} \cdot \mathbf{k} \cdot(\mathbf{2 I}+\mathbf{B})}{\mathbf{p}+\mathbf{I}}}{d \mathbf{p}}=\frac{k \cdot(2 I+B) \cdot(p+I)-p \cdot k \cdot(2 I+B)}{(p+I)^{2}}=\frac{I \cdot k \cdot(2 I+B)}{(p+I)^{2}}>0$. Hence if the VC chooses a share price lower than $p^{*}=k \cdot(2 I+B)-I$ in $t=1$, the share 
price in $t=2$ is lower than $p^{*}$, as well.

Let us assume that the share price the VC chooses is $\widetilde{p}$ where $\widetilde{p}<$ $k \cdot(2 I+B)-I$. Thus, the maximization problem of the $\mathrm{VC}$ is:

$$
\begin{aligned}
\max _{a} \pi_{l o c k}^{H}=\max _{a} a \cdot & \widetilde{p}+(1-a) \cdot \frac{\widetilde{p} \cdot k \cdot(2 I+B)}{\widetilde{p}+I}-I-2 B+B a-\epsilon= \\
& =\max _{a} a \cdot\left(\widetilde{p}-\frac{\widetilde{p} \cdot k \cdot(2 I+B)}{\widetilde{p}+I}+B\right)
\end{aligned}
$$

s.t.

$$
0 \leq a<1
$$

Let us distinguish three cases:

(i) If $\widetilde{p}-\frac{\widetilde{p} \cdot k \cdot(2 I+B)}{\widetilde{p}+I}+B<0$, then the VC's profit is maximized for $a=0$. The profit then reaches $\frac{\widetilde{p} \cdot k \cdot(2 I+B)}{\widetilde{p}+I}-I-2 B-\epsilon$, which is less than $k \cdot(2 I+B)-2 I-2 B-\epsilon$, which is less than the profit under $p^{*}$ and $a^{*}$.

(ii) If $\widetilde{p}-\frac{\widetilde{p} \cdot k \cdot(2 I+B)}{\widetilde{p}+I}+B=0$, then the profit is $\frac{\widetilde{p} \cdot k \cdot(2 I+B)}{\widetilde{p}+I}-$ $I-2 B-\epsilon$, which is less than under $p^{*}$ and $a^{*}$.

(iii) If $\widetilde{p}-\frac{\widetilde{p} \cdot k \cdot(2 I+B)}{\widetilde{p}+I}+B>0$, the profit is maximized for $a=\frac{B}{(\widetilde{p}+B)}$ if the $\mathrm{VC}$ wants to separate and for $a=1$ if the $\mathrm{VC}$ prefers pooling. In the latter case, we have no lock-up but a complete IPO. In the former case,

$$
\begin{aligned}
\max _{p} \pi_{\text {lock }}^{H} & =\max _{p} \frac{B}{p+B} \cdot p+\left(1-\frac{B}{p+B}\right) \cdot \frac{p \cdot k \cdot(2 I+B)}{p+I} \\
& -I-2 B+B \frac{B}{p+B}-\epsilon= \\
& =\max _{p}\left(1-\frac{B}{p+B}\right) \cdot \frac{p \cdot k \cdot(2 I+B)}{p+I}
\end{aligned}
$$

s.t.

$$
0<p<k \cdot(2 I+B)-I
$$




$$
p-\frac{p \cdot k \cdot(2 I+B)}{p+I}+B>0
$$

The profit is an increasing function of the share price since $\frac{d \pi_{\text {lock }}^{H}}{d p}>0$. Therefore, the VC chooses the highest possible price given the constraint: $p<k \cdot(2 I+B)-I$. His profit is then lower than under $p^{*}$ and $a^{*}$.

\section{Appendix F}

\section{Type H: Lock-up vs. Complete IPO Under Asymmetry}

The VC's profit when financing an H-firm:

Complete IPO:

$$
\begin{aligned}
& \pi_{i p o}^{H}(t \mid t=1) \leq \frac{k \cdot(2 I+B)}{2}-2 I-B-\epsilon \\
& \pi_{i p o}^{H r}(t \mid t=2)=(k-1) \cdot(2 I+B)+k \cdot I-I-B+r k B-\epsilon
\end{aligned}
$$

Lock-up with $p^{*}$ and $a^{*}$ :

$$
\pi_{\text {lock }}^{H}=(k-1) \cdot(2 I+B)-B-\epsilon+B \cdot \frac{B}{k \cdot(2 I+B)-I+B}
$$

Lock-up with $p^{*}$ and $a^{*}$ is preferred to an IPO in $t=2$ when $\pi_{\text {lock }}^{H}-\pi_{i p o}^{H r}(t \mid t=2) \geq 0 \Leftrightarrow B \cdot \frac{B}{k \cdot(2 I+B)-I+B}+I-k I-r k B \geq 0 \Leftrightarrow r \leq r^{* *}$.

Lemma: Lock-up with $p^{*}$ and $a^{*}$ is always preferred to a complete IPO in $t=1$ since:

$\pi_{\text {lock }}^{H}-\pi_{\text {ipo }}^{H}(t \mid t=1) \geq \frac{1}{2} \cdot k \cdot(2 I+B)-B+B \cdot \frac{B}{k \cdot(2 I+B)-I+B}>0$.

\section{Proof:}

Obviously, $\quad 2 B I>k \cdot(2 I+B) \cdot \underbrace{[(2 I+B) \cdot(1-k)-I]}_{\text {negative }}$ 
After rearranging terms we get the desired inequality.

$$
\begin{aligned}
2 B I>I k(2 I+B)+2 k B(2 I+B)-k B(2 I+B)-k^{2}(2 I+B)^{2} \\
2 B I-2 k B(2 I+B)>k(2 I+B) \cdot(I-B-k \cdot(2 I+B)) \\
\frac{2 B(k \cdot(2 I+B)-I+(+B-B))}{k \cdot(2 I+B)+B-I}<k(2 I+B) \\
k(2 I+B)-2 B\left(1-\frac{B}{k \cdot(2 I+B)+B-I}\right)>0 \\
\frac{B}{2} \cdot k \cdot(2 I+B)-B+B \cdot \frac{B}{k \cdot(2 I+B)-I+B}>0,
\end{aligned}
$$

which is the inequality we wanted to get.

\section{Appendix G}

\section{Comparative Statics}

For $r \leq r^{* *}$ an H-type prefers lock-up, for $r>r^{* *}$ he favors IPO in $t=2$. For $r \leq r^{* *}$ the fraction sold by the $\mathrm{VC}$ in $t=1$ is $a^{*}$ and the share price is $p^{*}$ in equilibrium. For $r>r^{* *}$ that is sold in $t=2$, the price per share is denoted by $p_{2}$.

The fraction $a^{*}$ sold in $t=1$ :

$$
\begin{aligned}
& \frac{d \mathbf{a}^{*}}{d \mathbf{B}}=\underbrace{\frac{\overbrace{2 k I-1}^{\text {positive }}}{(B-I+k B+2 k I)^{2}}}_{\text {positive }}>0 ; \quad \frac{d \mathbf{a}^{*}}{d \mathbf{I}}=\underbrace{\frac{\overbrace{-B(2 k-1)}^{\text {negative }}}{(B-I+k B+2 k I)^{2}}}_{\text {positive }}<0 ; \\
& \frac{d \mathbf{a}^{*}}{d \mathbf{k}}=\frac{\overbrace{-B(2 I+B)}^{\text {negative }}}{\underbrace{(B-I+k B+2 k I)^{2}}_{\text {positive }}}<0 .
\end{aligned}
$$

The price $p^{*}$ in $t=1$ :

$\frac{d \mathbf{p}^{*}}{d \mathbf{B}}=k>0 ; \quad \frac{d \mathbf{p}^{*}}{d \mathbf{I}}=2 k-1>0 ; \quad \frac{d \mathbf{p}^{*}}{d \mathbf{k}}=2 I+B>0$.

The price $p_{2}$ in $t=2$ :

$\frac{d \mathbf{p}_{2}}{d \mathbf{B}}=2 k>0 ; \quad \frac{d \mathbf{p}_{2}}{d \mathbf{I}}=3 k-1>0 ; \quad \frac{d \mathbf{p}_{2}}{d \mathbf{k}}=3 I+2 B>0$. 
The break-even point $r^{* *}$ :

$$
\begin{aligned}
& \frac{d \mathbf{r}^{* *}}{d \mathbf{B}}=\frac{\overbrace{I\left(I^{2}(1-2 k)^{2}(k-1)+B^{2}\left(-2+k+k^{2}+k^{3}\right)+2 B I(2 k-1)\left(k^{2}-1\right)\right)}^{\underbrace{B^{2} k(B-I+B k+2 I k)^{2}}_{\text {positive }}}}{\underbrace{2}}>0 \text {; } \\
& \frac{d \mathbf{r}^{* *}}{d \mathbf{I}}=\frac{\overbrace{1-k+\frac{B^{2}(1-2 k)}{(B-I+B k+2 I k)^{2}}}^{\text {negative }}}{\underbrace{B k}_{\text {positive }}}<0 \\
& \frac{d \mathbf{r}^{* *}}{d \mathbf{I}}=-\left(\frac{\overbrace{I^{3}(1-2 k)^{2}+B^{2} I k(6+k)+B^{3}(1+2 k)+2 B I^{2}\left(-1+k+2 k^{2}\right)}^{\text {positive }}}{\underbrace{B k^{2}(B-I+B k+2 I k)^{2}}_{\text {positive }}}\right)<0 .
\end{aligned}
$$

